\title{
Application of automated lineament analysis of satellite images in modern geodynamics research: A case study
}

\author{
V. N. Zakharov ${ }^{1}$, A. V. Zverev ${ }^{2}$, A. T. Zverev², V. A. Malinnikov², and O. N. Malinnikova ${ }^{1}$ \\ Received 15 May 2017; accepted 5 June 2017; published 15 September 2017.
}

This article describes the experience of geodynamic zoning of the Earth's crust and detection of its block structure based on the multi-scale automated lineament analysis of satellite images. The uniform blocks in the crust typically have similar patterns of rose diagrams of lineaments. The patterns change at the intersection of a morphostructural lineament between heterogeneous blocks. Stress state of the Earth's crust blocks is assessed by the schemes of densities of lineaments (strokes): as a rule, zones of the increased density of lineaments are related with tension while zones of the decreased density of lineaments are connected with compression. Flow paths of interstitial water are traced by the presence of zones of the increased density of lineaments (strokes) oriented across river valleys. The risk of landsliding is defined by the existence of zones of interstitial water flow paths toward the outlets in river valleys. Earthquakes are predicted by the lineament analysis of satellite images obtained a few months before and after an earthquake. Before an earthquake, the form of the rose diagrams and the ratio between the lengths of lineaments of different extend regularly change. KEYWORDS: Lineament analysis; rose diagram; geodynamic zoning; earthquakes; landslides; faults; compression and tension zones; satellite images.

Citation: Zakharov, V. N., A. V. Zverev, A. T. Zverev, V. A. Malinnikov, and O. N. Malinnikova (2017), Application of automated lineament analysis of satellite images in modern geodynamics research: A case study, Russ. J. Earth. Sci., 17, ES3001, doi:10.2205/2017ES000599.

\section{Introduction}

Thanks to the rapid development of the Earth remote sensing equipment, much attention is currently devoted to satellite surveys to detect and analyze lineaments (linear discontinuities in the Earth's crust and lithosphere, of different rank, length, depth and age) and ring structures (as a rule, geological bodies with the center of symmetry, of different nature and age) [Nechaev, 2010]. Studies of linear and ring structures are of importance for practical evaluation of jointing over large areas, detection of groundwater flow paths, search of new mineral deposits, prediction of hazardous phenomena and events, or selection of sites for heavy-duty construction (atomic power plants, underground radioactive waste storages, sports structures, highways, tunnels etc).

\footnotetext{
${ }^{1}$ Institute of Integrated Mineral Development, Russian Academy of Sciences, Moscow, Russia

${ }^{2}$ Moscow State University of Geodesy and Cartography, Moscow, Russia

Copyright 2017 by the Geophysical Center RAS.

http://elpub.wdcb.ru/journals/rjes/doi/2017ES000599-res.html
}

It is generally admitted that identification of linear and ring structures on the surface of the Earth and other celestial bodies of the Solar system using satellite images is of subjective nature to a great extent, and often requires much time and energy. Automated identification of lineaments and ring structures enables overcoming these difficulties and features high operating efficiency, economic effectiveness and objectiveness. On the other hand, the current approaches to the automated detection and analysis of lineaments and ring structures have a number of disadvantages among which the most serious faults are low reliability of automated-identified lineaments and ring structures, limited capabilities of computer-aided detection of linear and ring structures that are slightly seen or unevenly illuminated in images, scanty means of integration of differentnature and different-level geo-data used for the automated detection and analysis of linear and ring structures [Politaev, 2001 Zlatopolsky, 2008. In this connection, it seems of the current concern to create a higher-end technology of the computer-aided identification and analysis of lineaments and ring structures in satellite images with a view to overcoming limitations inherent to computer-aided techniques. 


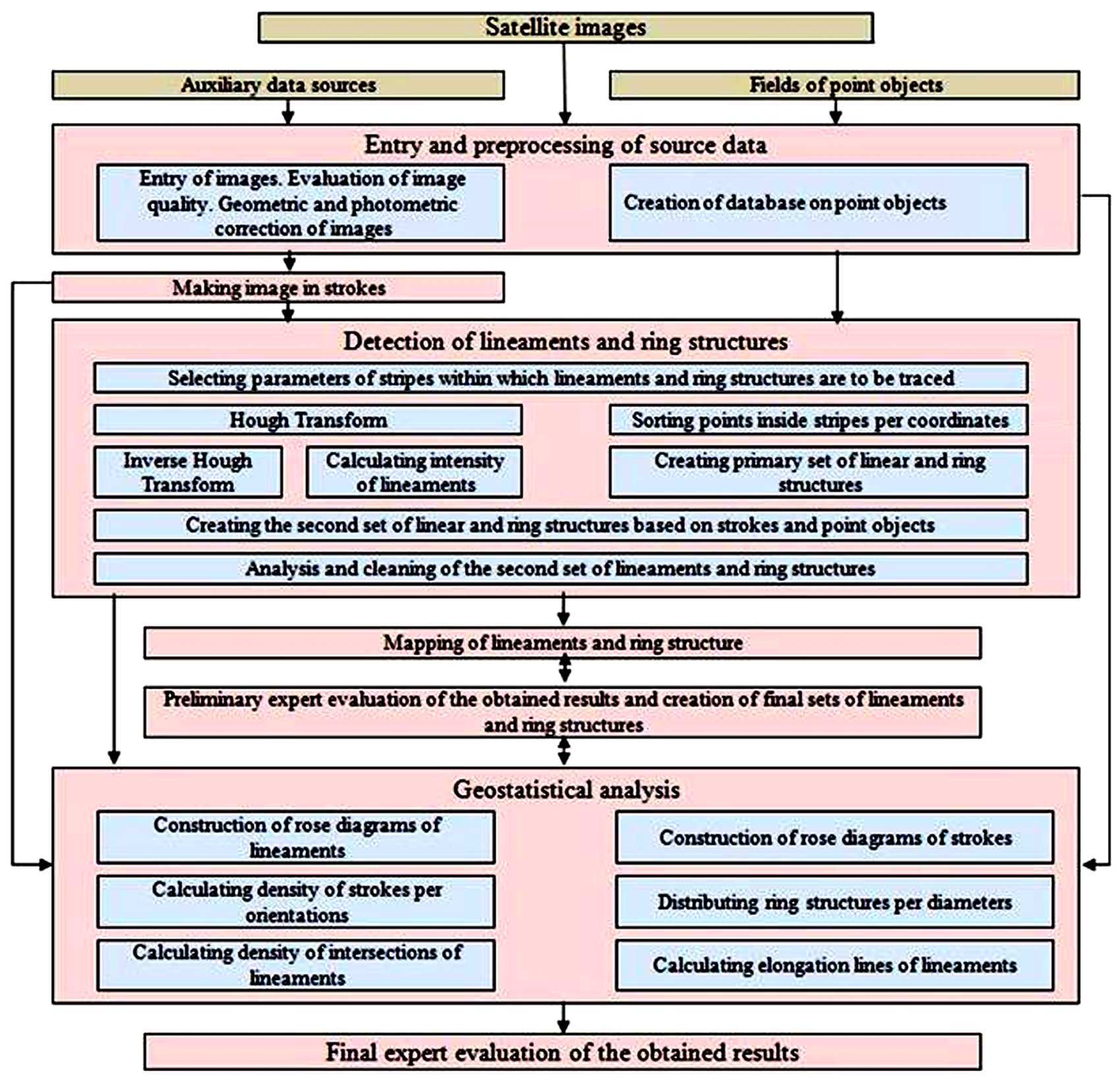

Figure 1. Process chart of automated detection and analysis of lineaments and ring structures in satellite images.

Brief Description of the Image Processing Technology

The computer technology of detection of lineaments and ring structures contains seven stages (Figure 1): entry and preprocessing of data; making images in strokes; identification of lineaments and ring structures; mapping of lineaments and ring structures; preliminary expert analysis of the results and formation of final sets of lineaments and ring structures; geostatistical analysis of strokes, lineaments and ring structures; final expert evaluation of the results [Malinnikov, 2011.
The first stage of the technology is entry and preprocessing of input data which are the satellite images of the area under study and the digitized images of fields of point objects (volcanic piles, hydrothermal sources, epicenters of earthquakes etc).

In the course of preprocessing of available satellite images, a mosaic of digital images containing fragments of the source satellite images of the area under analysis, subjected to correction in terms of geometry or brightness if necessary, is generated. Furthermore, in case that the data of the geology of this area are available, an auxiliary database on point objects is created. 


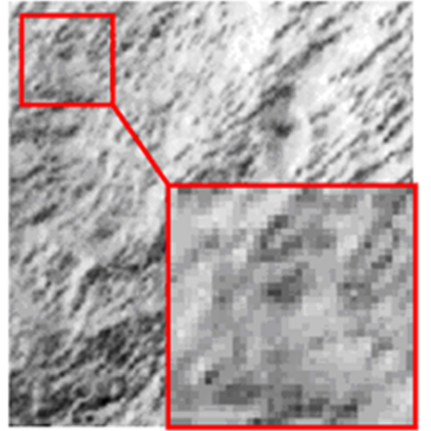

Original image and zoomed-up fragment

5.

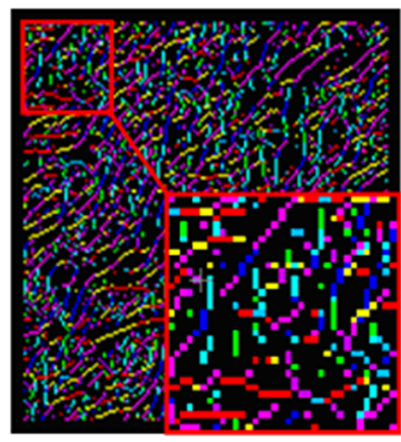

Image in strokes after standardization of response of each element in image 4 and subsequent filtering

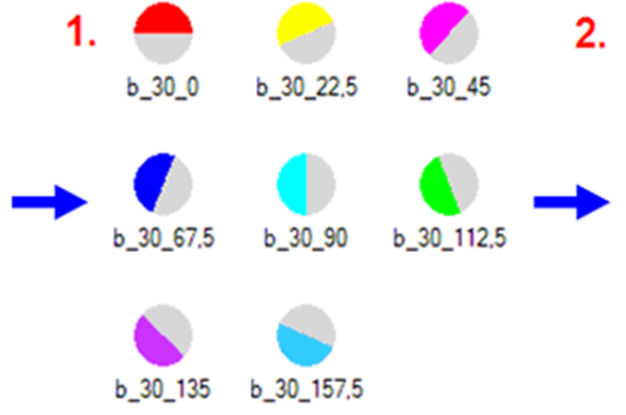

Set of masks «Straight-line

boundary" to detect strokes of eight basic orientations
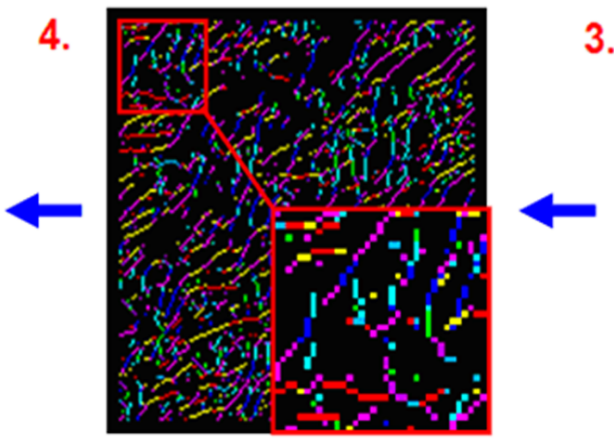
Image in strokes after reduction of image 3 to the eight-track form

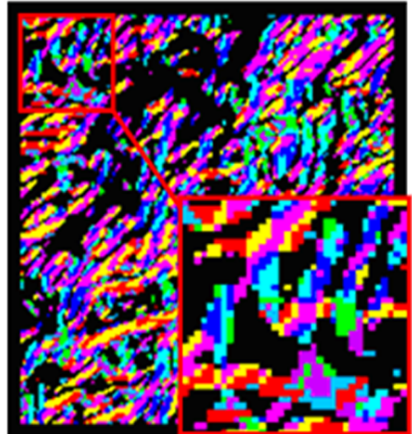

Image of peak responses after folding of the original image with the preset masks

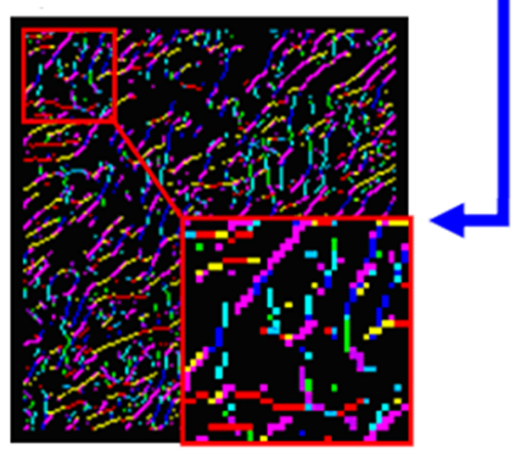

Image in strokes after thinning the image of peak responses

Figure 2. Fragment of the test image and images in strokes at different stages of processing.

The second stage of the technology is making a supporting image in strokes. The generalized algorithm of stroke imaging belongs in the class of algorithms of edge detection in digital images by means of oriented masks, and has two significant advantages over the other mask algorithms [Zlatopolsky, 2008]:

- Preservability of information on the orientation of a stroke (in case of a linear structure detected), or about the direction to the center of a circle (in case of a ring structure) at each point of the supporting image in strokes;

- Detectability of the elements of linear and ring structures with the preset characteristics of geometry and/or brightness.

Figure 2 presents a test pattern and stroke images by stages of the generalized algorithm implementation.

Under the proposed generalized algorithm, in a digital image, a set of masks (of the same or different types) is formed, and threshold values of the parameters linearity and contrast are determined. The involved types of the masks are Stripe, Straight-line boundary and Curved boundary. The formulas to calculate weight factors of these masks are given in Table 1.

In the Table 1 there are $-m \leq u, \nu \leq m, R_{m}=m+0.51$, $m$ - radius of a mask window; $a=1 / n_{1}, b=1 / n_{2}, n_{1}, n_{2}$ - quantity of positive and negative elements in a mask; $k$ number of a mask $\left(k \in \overline{1, k_{m}}\right)$.

The most important stage of the technology is the detection of lineaments and ring structures based on the integrated analysis of the previous-stage digital image in strokes and the created database on point objects to show spatial position of point geological objects.

Later on, using the data on point objects, a primary set of linear and ring structures is formed using a certain algorithm. First, the field of points is split into stripes of a certain width and a database on the stripes is created using the identification numbers of the points belonging in the stripes obtained by turning the horizontal stripes by a preset angle. Then, the points within each stripe are sorted 
Table 1. Calculation Formulas for Weight Factors of Different-Type Masks

Type of mask $\quad$ Weight factor formula

Stripe $\quad e_{k}(u, v)=\left\{\begin{array}{c}0, \text { at } u_{2}^{2}+v_{2}^{2}>R_{m}^{2} \\ -a, \text { at }\left|(u-0.5) \sin \alpha_{k}+(v-0.5) \cos \alpha_{k}\right|>w \\ b, \text { at }\left|(u-0.5) \sin \alpha_{k}+(v-0.5) \cos \alpha_{k}\right| \leq w\end{array}\right\}$

where $w=R \sin (C / 2+0.001)$ - width of a stripe $R=D_{\min } / 2+0.51 ; C$ - width of an

angular sector $(w \geq 1 / \sin C) ; \alpha_{k}=180(k-1) / k_{m}$ - slope of the stripe $\left(k_{m} \leq 180\right)$

Curved boundary $\begin{aligned} & 0, \text { at } u_{2}^{2}+v_{2}^{2}>R_{m}^{2} \\ & e_{k}(u, v)=\left\{\begin{array}{c}-a, \text { at }\left(u-R \sin \alpha_{k}\right)^{2}+\left(v-R \cos \alpha_{k}\right)^{2} \leq R^{2} \\ b, \text { at }\left(u-R \sin \alpha_{k}\right)^{2}+\left(v-R \cos \alpha_{k}\right)^{2}>R^{2}\end{array}\right\} \\ & \text { where } R \in\left[R_{\min }, R_{\max }\right], R_{\min }=D_{\min } / 2, R_{\max }=D_{\max } / 2, \text { where } D_{\min }, \\ & D_{\max }-\text { minimum and maximum diameters of arcs detected in the image; } \\ & \alpha_{k}=360(k-1) / k_{m}-\text { slope of a tangent to the detected arc }\left(k_{m} \leq 360\right)\end{aligned}$

$\begin{aligned} & \text { Straight-line boundary } e_{k}(u, v)=\left\{\begin{array}{c}0, \text { at } u_{2}^{2}+v_{2}^{2}>R_{m}^{2} \\ -a, \text { at }(u-0.5) \sin \alpha_{k}+(v-0.5) \cos \alpha_{k} \leq 0 \\ b, \text { at }(u-0.5) \sin \alpha_{k}+(v-0.5) \cos \alpha_{k}>0\end{array}\right\} \\ & \text { where } \alpha_{k}=360(k-1) / k_{m}-\operatorname{slope} \text { of a boundary sector detected by a mask }\left(k_{m} \leq 360\right)\end{aligned}$

with respect to the increase in the geographical coordinate.

At the next step, for each stripe, two sequences of points for which the distance between the next two points is not higher than a certain threshold value are identified. The first and the last points in each of the sequences are connected by a line (called segment), the end coordinates of the line are entered in the database on the stripes. The points outside of any segment are excluded from the database on stripes. When the density of points in the field under analysis is high, it is possible that through lineaments are detected inside the stripes of the pre-set width and slope. It is necessary to seek for chains of closely spaced points such that terminal points of these chains lie nearby the edges of the image studied. At the next step, the repeated and excess segments are identified by some means or other, and are removed from the database on stripes. Finally, the database on stripes is cleaned from the segments having no significant distinctive features in the framework of the current task. The resultant set of segments can be assumed the primary set of lineaments, which specifies regularities of physical layout of point objects, characterizing geological structure of the region under study. After that, long lineaments (through lineaments) are identified in the field of strokes from the first stage of the satellite image analysis. The automated detection of lineaments and ring structures uses an algorithm based on the Hough Transform. In this algorithm, the initial image in strokes is transferred to a plane where all points of strokes belonging to a straight line or a circle are imaged as one point with coordinates.

The final sets of linear and ring structures are visualized in the form of maps. Based on the mapped data, an expert performs the preliminary analysis, cleans the second set of linear and ring structures from the structures that are topographical or geological lineaments, according to an expert's opinion, and adds the mentioned second set with the structures undetected by computer.

The final stage of the technology is the geostatistical analysis of lineaments and ring structures as well as strokes obtained at the second stage of the technology. This analysis reveals statistical regularities in the physical layout of lineaments and ring structures across the whole area under study or inside specified domains, and allows additional information on the resultant set of linear and ring structures. The statistical analysis of lineaments and fields of strokes may include estimation of density and frequency of strokes, lineaments and their intersections in space, plotting of rose diagrams of stokes and lineaments as well as assessment of spacing of lineaments. In case of ring structures, the statistical analysis may involve estimation of frequency and density of ring structures in space as well as statistical characteristics of their distribution per diameters.

The technology proposed for the automated detection and analysis of linear and ring structures has been implemented using specially designed and tested program modules [Savinykh et al., 2012]:

- Program module (plug-in) to detect lineaments and ring structures - Lineament and Circular Structures Detector (LCSD);

- Program module (plug-in) to analyze lineaments and ring structures-Lineament and Circular Structures Analyser (LCSA).

Figure 3 shows the flow chart of imaging fields of strokes for the detection and analysis of lineaments and ring structures. 


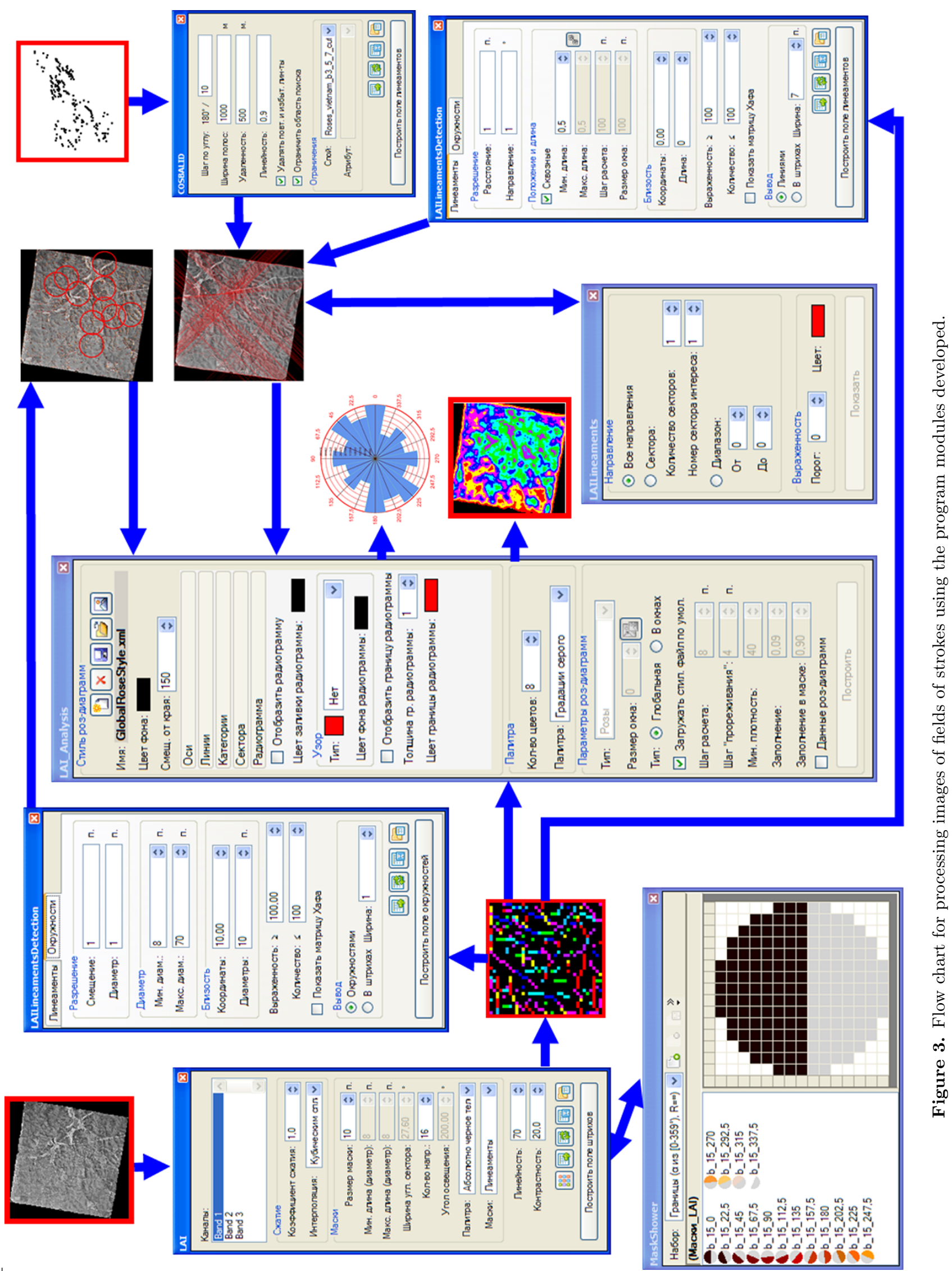




\section{Experimental Studies}

The studies carried out by the authors of this paper have proved efficiency of the proposed technology for the automated analysis of lineaments in satellite images by the high conformity between the results obtained with the use of the technology and the data of actual geological and geophysical research, structure-and-tectonics maps and the information the authors gained during field surveys. Lineaments are best identified in the small-scale images of mostly deepseated and regional faults. The large-scale images mainly show shallow local faults. The maximum credible detection of faults is possible with the set of small-, medium- and large-scale satellite images so that the small-scale images are the basis while the medium- and large-scale images are the supplement.

The research accomplished in the recent decades in the framework of the new school of modern geodynamics prove demonstratively that the modern deformation processes in the zones of active faults are highly hazardous for a human being and its living environment. On the geodynamic testing grounds arranged in the basins of sedimentary rocks containing oil and gas, a new class of tectonic movements has been detected - modern super-intensive deformation (SD) of the Earth's surface. In the areas of oil and gas reservoirs, it has been revealed that SD-processes considerably contribute to accidents at production objects and participate in the formation and reformation of the reservoirs, their fluid flow, anomalous reservoir pressures etc. The current short-period (first months and years) pulsating and/or alternating SD-processes on the ground surface have annual rates not less than $10^{-5}$. The present study has demonstrated that the automated detection and analysis of lineaments most efficiently identifies, first of all, active faults as against the other methods used to detect faulting. The discussed technology allows a system analysis on the basis "from the general to the special", which enables identification of a hierarchically ordered structure of lineaments and blocks in any area of interest using different and disembodied geological and geophysical data.

Below in this paper, the case studies of applying the lineament analysis of satellite images for detection of block structure, modern active faults, zones of high jointing and landsliding as well as groundwater flows in rock mass are described.

\section{Geodynamic Zoning}

Geodynamic zoning allows efficient and prompt assessment, prediction and control of rock mass condition at any stage of underground or surface development. Geodynamic zoning in based on the identification of block structure of the subsoil, active faults and their intersections, zones of high tectonic stresses, as well as on the analysis of various geotechnical characteristics of rocks and geo-environment, which enables predictive mapping of stress state of rocks with regard to the impact of industry, and ensures preven- tive control towards sound mineral mining or efficient drivage when constructing tunnels, mines and other underground objects [Kats and Poletaev, 1986].

Area of the research. The Baikal Tunnel $6682 \mathrm{~m}$ long is driven in parallel to the existing tunnel under Davan passage of the Baikal ridge. The new tunnel has the maximum depth of $300 \mathrm{~m}$ under the saddle of Davan passage (stake 10079) at the average depth of $180 \mathrm{~m}$ along the tunnel (Figure 4). The Baikal Tunnel intersects magmatic rock mass. Tectonically, this section of rock mass occurs in the regional zone of a deep fault, or in Davan shear zone, with far and wide tectonic dislocations in the form of overthrusts, intensive fracturing and mylonitization, or neotectonic sutures.

Procedure of the research. Geodynamic zoning has been implemented using statistical characteristics of systems of lineaments after the automated analysis of satellite images.

The study of the oriented characteristics starts from the identification of linear elements - rectifiable boundaries or lines with a length of 10 pixels. The boundaries of rock blocks are defined by the change in the form or orientation of axes of rose diagrams of strokes, which are single-type within the same block. Using satellite images of different spatial resolution allows identifying blocks of different hierarchical levels.

The source information was selected to be a satellite image obtained after synthesis of 2,3 and 5 spectral channels LANDSAT-5. Using the automated lineament analysis technology, the authors have studied through lineaments, total density of strokes, density of strokes oriented along and across the main morphostructures, vectors and elongation lines of rose diagrams of strokes at the spatial resolution of $30 \mathrm{~m} /$ pixel and generalized modification of $60 \mathrm{~m} / \mathrm{pixel}$ of the original image.

From the evidence of the lineament analysis Figure 5 Figure 9, northeastward-oriented lineaments prevail in the area under study. These morphostructural lineaments divide the crust into a series of narrow blocks extended northeastward. The predominance of this orientation in the region is observed on the USSR geological map at a scale of $1: 1,000,000$. As compared with the geological map, the field of lineaments revealed by the lineament analysis of LANDSAT image offers a more detailed picture of the crust block structure and fracturing. Alongside with that, a sublatitudinal lineament southwards the tunnel and three diagonal northwestward morphostructural lineaments are observed.

The Baikal Tunnel lies at the intersection of two diagonal northeastward and northwestward lineaments conformable with the active faults, i.e. in the zone of possible local stress concentration and the related ground movements.

Rock mass in the area under study is mainly composed of the Pre-Cambrian granites and grano-syenites that break through the Pre-Cambrian metamorphic rocks westwards the tunnel. The governing role of the intrusive rocks and the related primary tectonics (zones of fractures generated during the intrusion) conditioned the complicated branching nature of elongation lines of rose diagrams of strokes. 


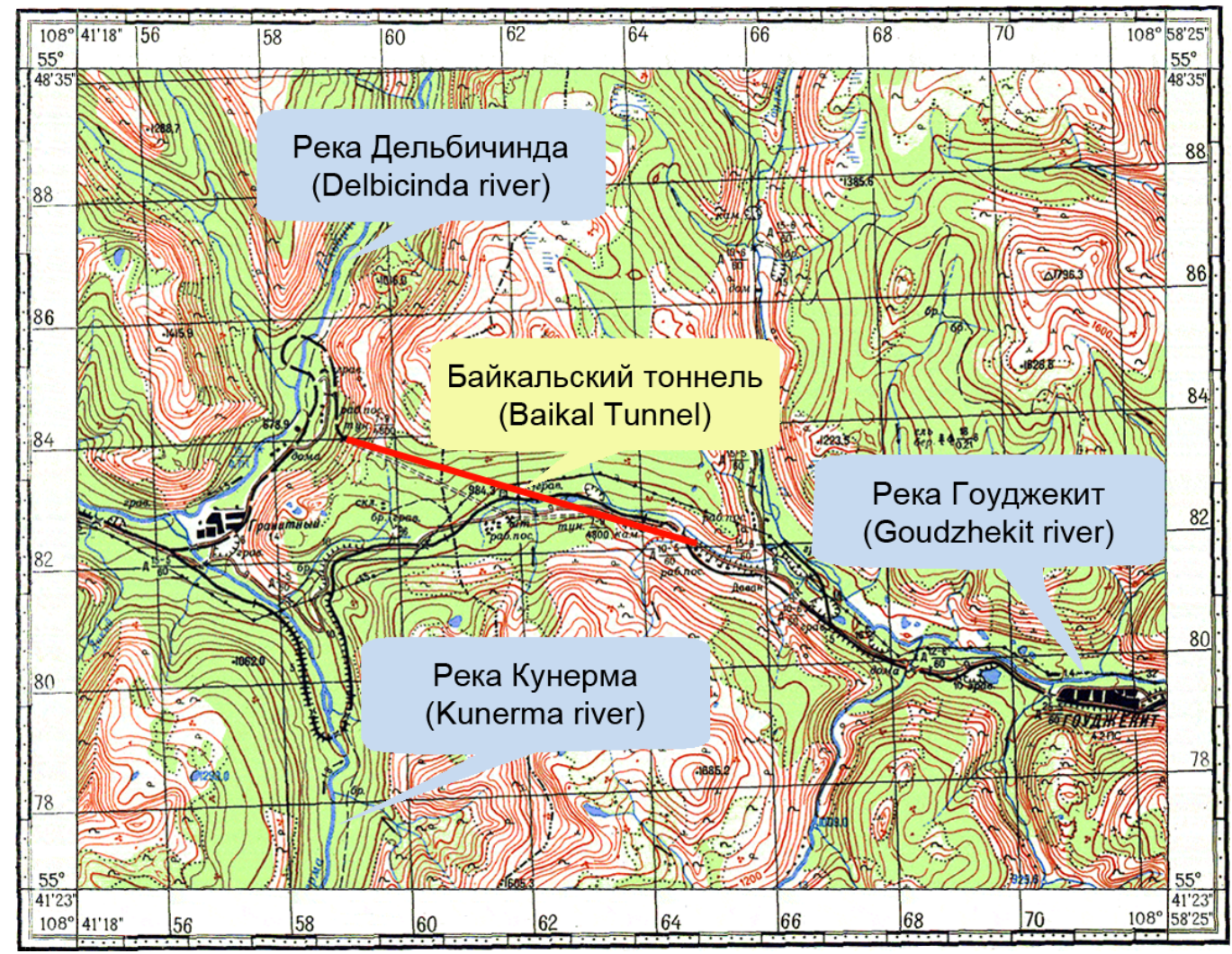

Figure 4. The area of the Baikal Tunnel construction, general geographic map.

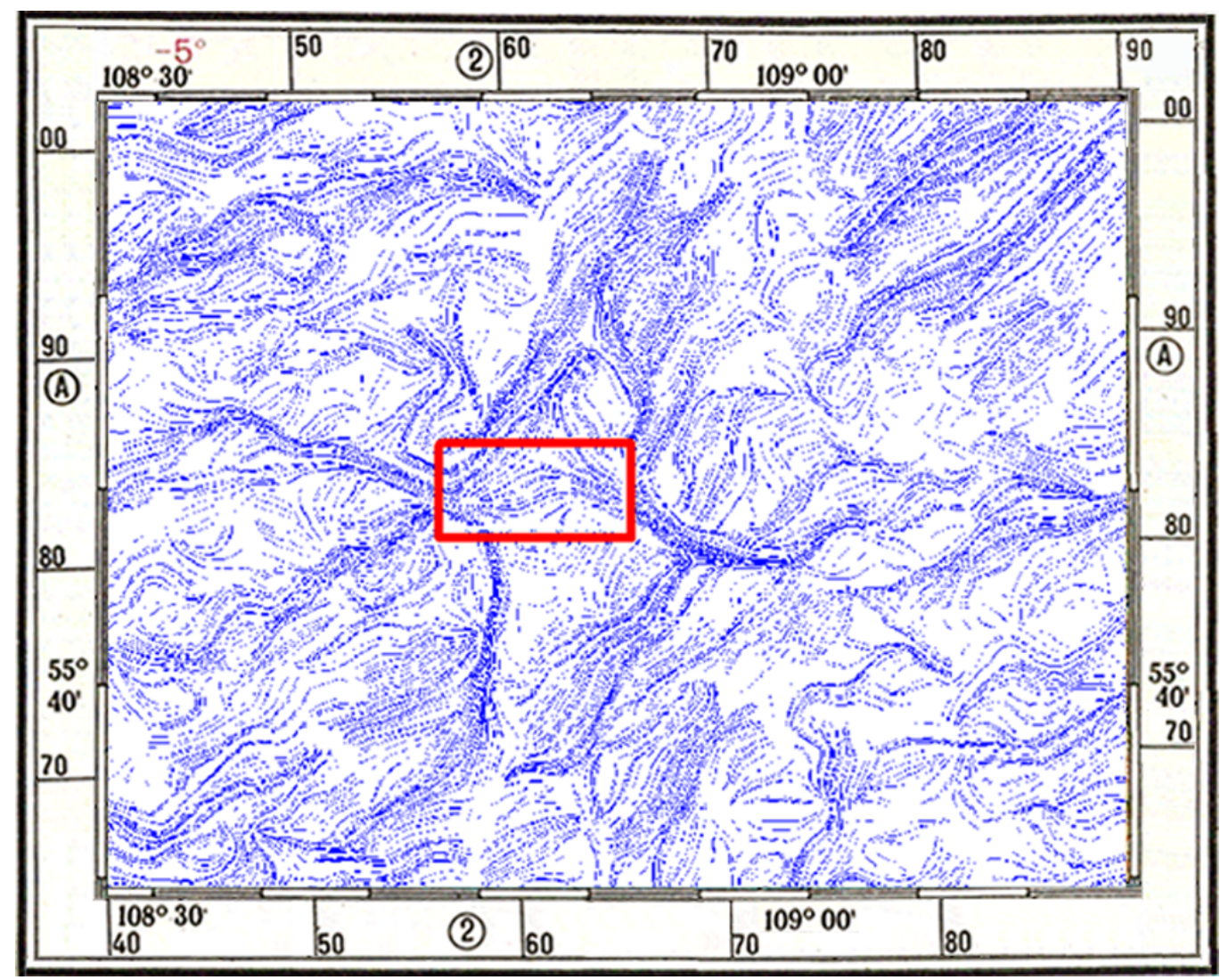

Figure 5. Elongation lines of rose diagrams of strokes. 


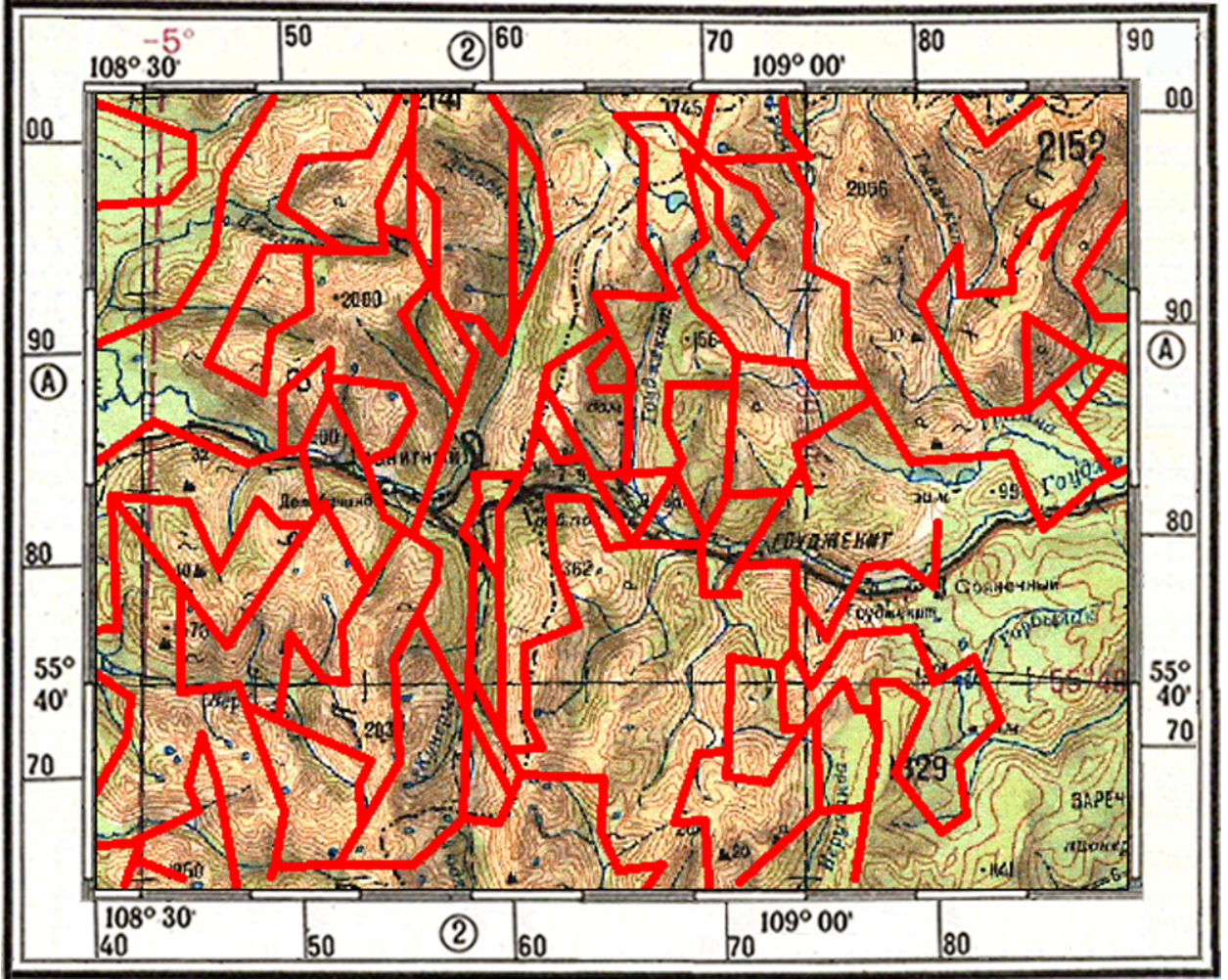

Figure 6. Third order faults between blocks with different orientations of rose diagrams of strokes.

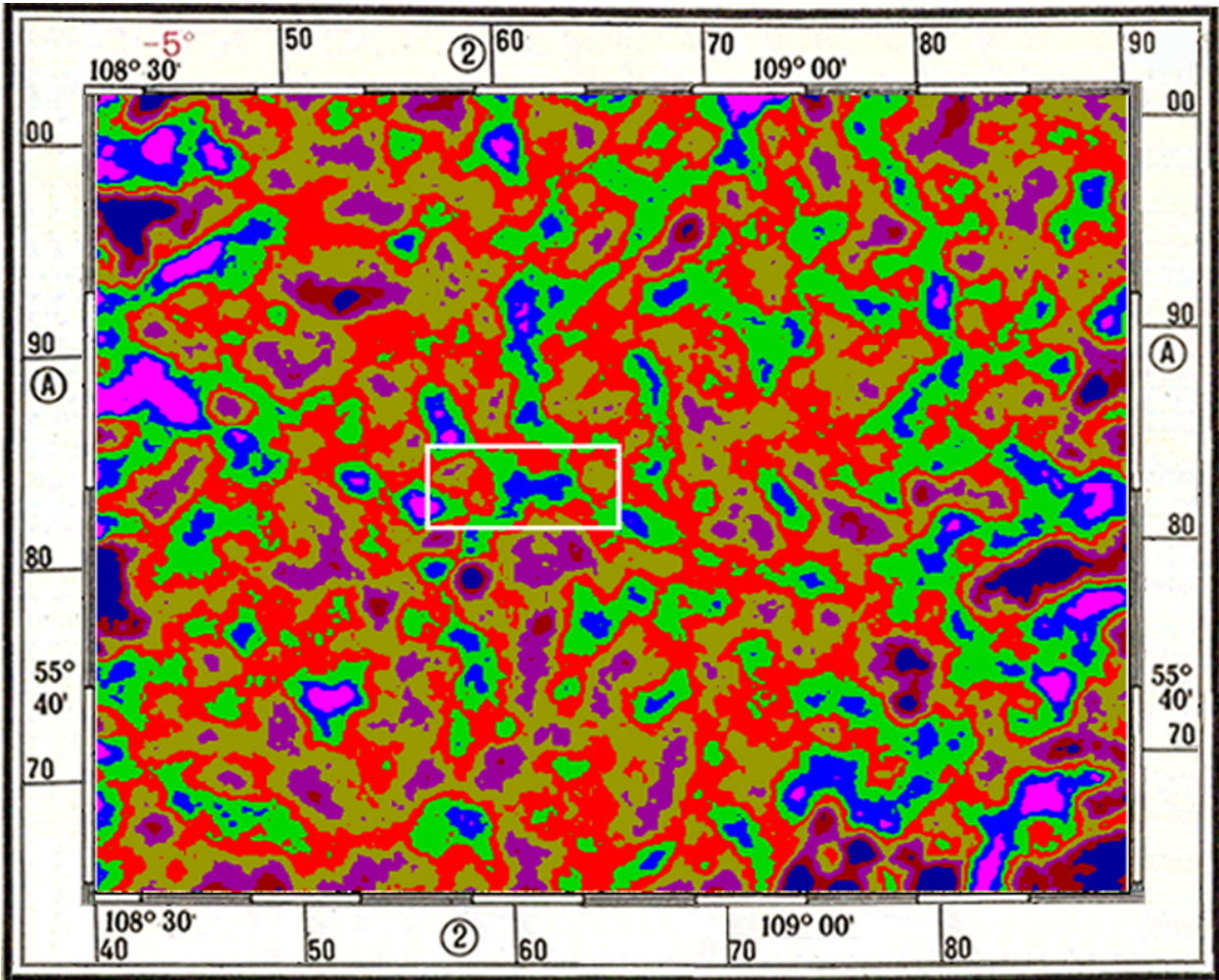

$\min$

\section{$\max$}

Figure 7. Total density of strokes of all orientations. 

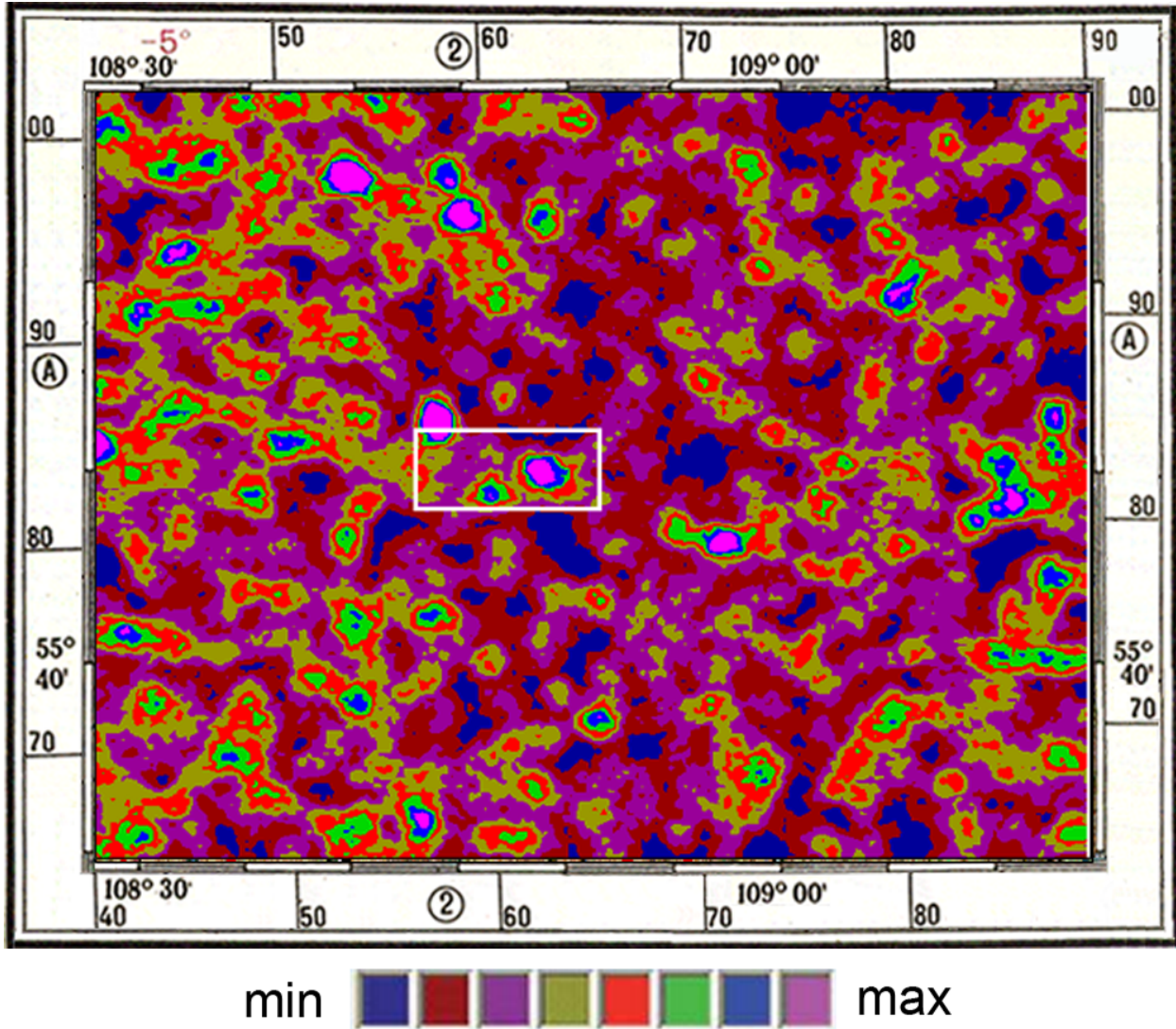

Figure 8. Density of strokes (local lineaments) oriented in the line of $0^{\circ}$.

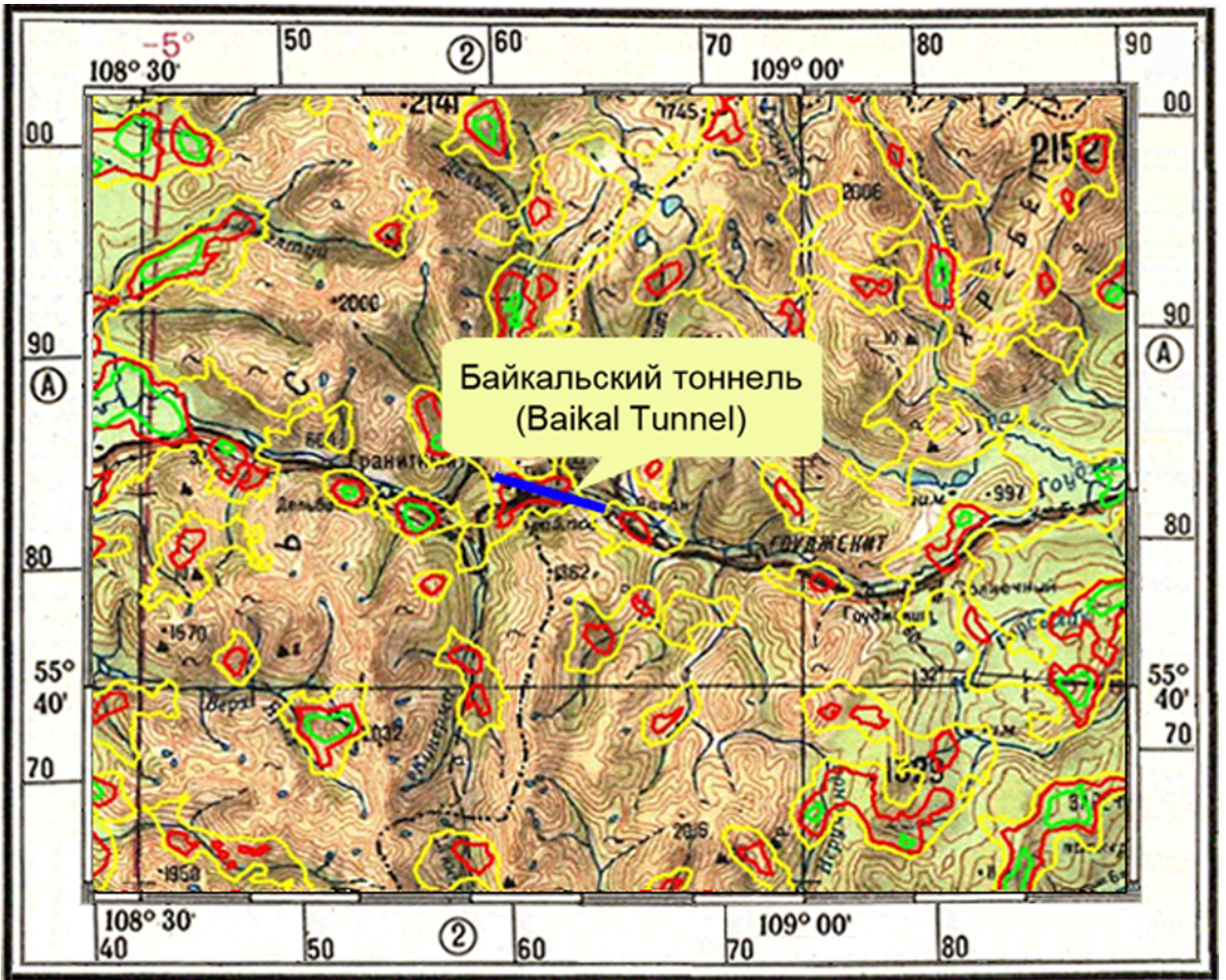

Figure 9. Schematic of stress field: (a) area of the Baikal Tunnel construction; (b) the tunnel site; tension zone 1 (yellow); stable zone 2 (red); compression zone (green). 
The through lineaments and the elongation lines of the rose diagrams conform with the morphostructural lineaments of the first and second order, respectively. Aiming to reveal higher order faults and blocks, it is advisable to use jointly rose diagrams of strokes and diagrams of vectors of strokes characterizing value and orientation of elongation of the rose diagrams of strokes. These statistical figures will be close in value for uniform blocks and will differ for heterogeneous blocks. An abrupt change in the form of the rose diagrams and in their elongation orientation implies the transition to another block and the zone where the change takes place means a fault between the blocks. With the purpose to reveal blocks of the higher, third order, the authors have used the generalized LANDSAT satellite images with the resolution of $60 \mathrm{~m} /$ pixel. In the single-type pattern of the rose diagrams, a series of blocks divided by the third order faults is detected. The blocks have complex shapes of different size polygons. The Baikal Tunnel under construction occurs at the juncture of the blocks having rose diagrams of strokes of different form and orientation. Sublatitudinal lineaments prevail westwards, eastwards and northwards the tunnel. On the south of the tunnel, there is a large block with the vectors of strokes oriented northnortheastward (NNE) and northeastward (NE). The automated lineament analysis of the original LANDSAT image (spatial resolution of $30 \mathrm{~m} /$ pixel) shows that the large southern block has a heterogeneous structure and is composed of a few smaller blocks, having rose diagrams of strokes of different form and orientation, bounded by the fourth order faults.

It follows from the analysis of the total density of strokes throughout the area that higher density anomalies are adjacent to river valleys and undergo tension. Hillsides feature average values of density of strokes. The minimal density of strokes is observed in local areas of rock mass mostly southwards the Goudzhekit river.

Based on the revealed statistical behavior of lineaments of different hierarchical levels in the studied area, it is possible to distinguish between geodynamic regions of three types: 1 - regions of increased jointing of rocks exposed to high tension; 2 - regions of average density of joints under stable conditions of growth; 3 - regions of minimum jointing of rocks under compression.

The Baikal Tunnel occurs in the second type region of the intermediate geodynamic state. The adjacency of the tension zones, namely, valleys of the Goudzhekit and Delbichinda rivers, complicates the geodynamic situation and reduces stability of rock slopes.

The Goudzhekit river flows east-westward, and its tributaries in the region of the tunnel have submeridional thread of stream (NNE 0-20 ${ }^{\circ}$ ). For the geodynamic analysis, these orientations of the local and regional lineaments are of the highest concern since the major flow paths of interstitial water and slope processes in the valley of the Goudzhekit river have the crosscutting submeridional directions while they have the sublatitudinal directions across the valleys of the tributaries. In this regard, the schemes of density of strokes of different orientation have been examined. To this effect, the fields of density of strokes resulted from the automated lineament analysis of the LANDSAT-5 image in the lines of $0^{\circ}$ and $90^{\circ}$ have been used.

In the line of $0^{\circ}$, there are two anomalous areas having an increased density of strokes (local lineaments). One anomalous area lies in the zone of the tunnel, the other area occurs slightly northwards the Vakhtovy settlement. These areas of rocks of increased fracturing oriented across the slopes of the Goudzhekit river valley and the right tributary of the Delbichinda river are near the flow paths of interstitial water contributing to high-rate development of slope processes (landslides, solifluction, mudlfows etc), which may be a threat for the Baikal tunnel structure.

In the line of $90^{\circ}$, there is an anomalously high density of strokes along the left and right tributaries of the Goudzhekit river, namely, the rivers Delbichinda, Goudzheskit, Gramna, Kunerma and others, which are the zones of interstitial water outlets from the main morphostructures (mountain ridges) in the discussed area. The excessive wetting of the bedrock slopes in the valleys of the Goudzhekit river tributaries promotes activation of slope processes accompanied by the top downward displacement of rocks.

The lineament analysis yields that the route of the Baikal Tunnel intersects three zones of faulting bounding blocks with variously oriented lineaments not shown in the $1: 5000$ scale geological map. The first fault zone adjoins the West Portal (stake 10060), the second zone - between holes 7 and 8 near a cross connection, and the third zone occurs westwards the East Portal (stake 10127). These zones are the potential risk of deteriorative geo- and hydrodynamic processes. The boundaries of rockburst-hazardous sections are traced along the routes of the escape cross- connections near the Falls Stream, between holes 7 and 8 and westwards the East Portal (westward stake 10127) close to hole 22.

In the area under analysis and in its vicinity, three geodynamic regions in different stress state are distinguished: 1 - zones of tension, with high jointing (fracturing) of rock mass; 2 - intermediate zones with average density of lineaments; 3 - compression zones with minimal jointing (fracturing) of rocks. The Baikal Tunnel is located within the second zone. The adjacency of the tension zones adjoined by the valleys of the Goudzhekit and Delbichinda rivers complicates the geodynamic situation and reduces strength of mountain slopes.

In the east of the Baikal Tunnel, a zone of anomalously high density of lineaments oriented in the line of $0^{\circ}$, i.e. across the Goudzhekit river valley and bordering mountain slopes, is observed. This zone is the channel of interstitial water that outflows in the Goudzhekit river valley, which invites extra hazard.

The implemented geodynamic zoning shows that the major portion of the tunnel (north-west) occurs inside a comparatively stable geodynamic zone between the zones of tension (valley of the Goudzhekit and Delbichinda rivers) and compression (above the tunnel). However, the position of the tunnel at the intersection of the two active diagonal northeastward and northwestward faults is endangered by the probable local concentration of stresses and the related induced movement of rocks (geodynamic activity). The southwest portion of the tunnel partly falls in the tension zone. 
In the same zone, the anomalous section of increased density of local lineaments, implying probable local movements of rocks in this area, is observed. Another similar section lies near the tunnel, slightly northwards the Vakhtovy settlement. These zones of highly fractured rocks touch the paths of interstitial water flows, which contributes to highrate development of slope processes (landsliding, solifluction, mudflow etc).

\section{Analysis of the Dynamics of Lineament Systems in the Period Before an Earthquake}

This analysis is based on the method of earthquake prediction [Bondur and Zverev, 2005 that enables revealing the signs of change in the crust stress state by the observation data on lineaments using the automated analysis of regular satellite images.

The analysis is performed in terms of the 5.2 magnitude earthquake in the south of Peru on January 7, 2004. The involved visible-light and infrared-light images with a resolution of 15 and $30 \mathrm{~m}$ were recorded by ASTER (terra) equipment on September 21, 2003 (128 days before the earthquake), December 10, 2003 (48 days before the earthquake) and April 9, 2004 (73 days after the earthquake. The scope of the analysis also embraced a test area free from the observable seismic activity (Figure 10.

From the evidence of the lineament dynamics analysis, lineaments in the seismically active area are extremely dynamic: a few new lineaments appeared shortly before the earthquake mostly in the NE-SW direction across the principal geological and geomorphological elements of the Andes. Eventually, their appearance is an indicator of the change in the stress field and the accumulation of transverse strains in the period of the earthquake initiation.

Under stable tectonics, the system of lineaments is lean and almost the same in all images. The change in the threshold has no influence on the outcome: generation of new lineaments before the earthquake, relaxation in the zone around the epicenter after the earthquake and preservation of the system of lineaments in the zone far from the epicenter.

The studies of density of strokes along each preset orientation show that the fields obtained 48 days before the earthquake appreciably differ from the fields 128 before and 73 days after the earthquake while the fields of density of strokes in the aseismic test site remain the same. Aiming to highlight the phenomenon, the authors have calculated the difference between the pairs of the fields of densities. This allows neutralizing human factor and, partly, unevenness of the relief. The most significant feature is the presence of an extended zone where density of strokes increases in the line of $112.5^{\circ}$ and decreases in the line of $45^{\circ}$. After the earthquake, densities of strokes recover and the differences between the images recorded four months before the earthquake and two and a half month after it are insignificant Figure 11 and Figure 12.

The differences between the fields of density of strokes in

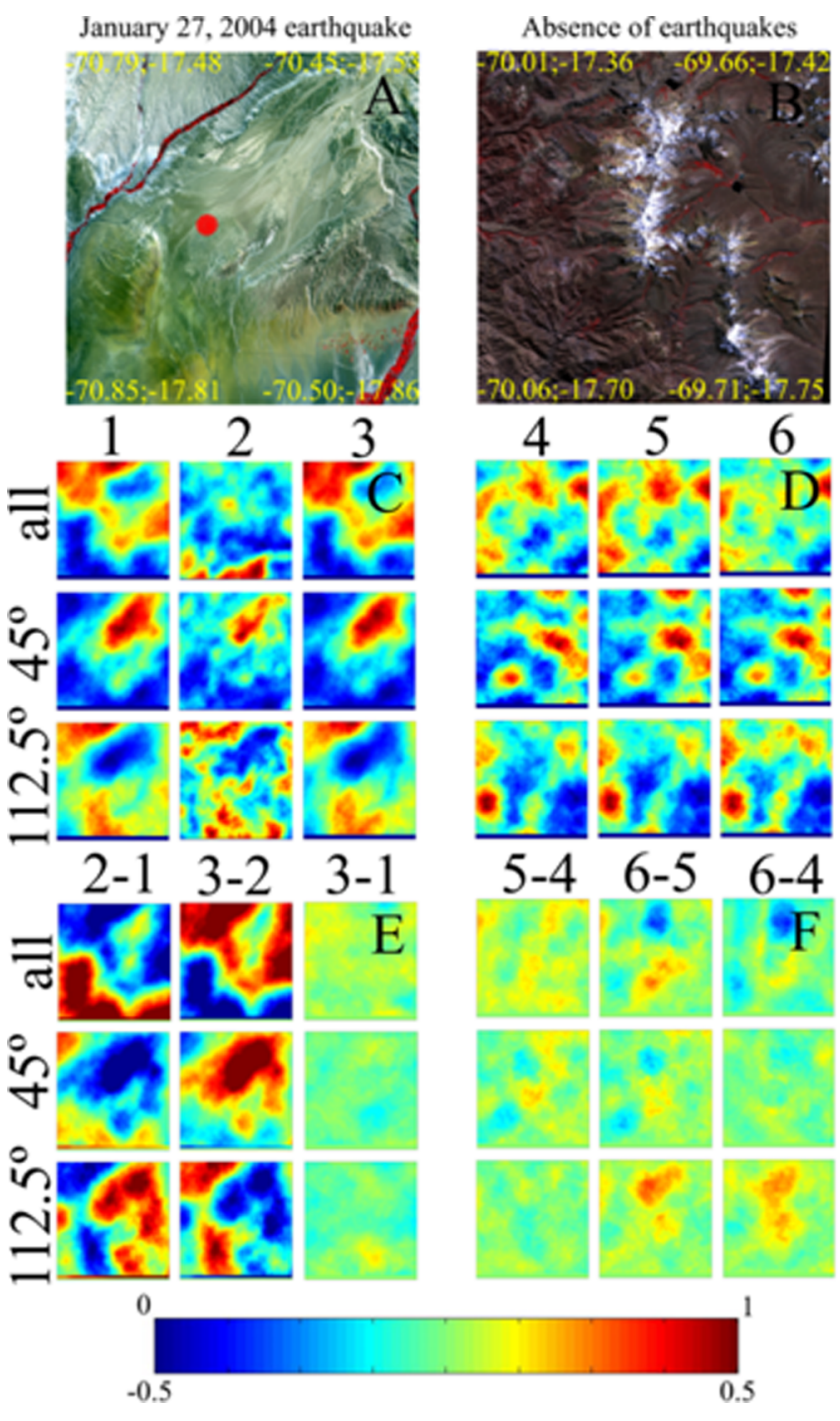

Figure 10. Pseudocolor ASTER images of (A) area of January 27, 2004 earthquake and (B) area without seismic activity. Densities of strokes at threshold 0 for all orientations and for orientations in the lines of $45^{\circ}$ and $112.5^{\circ}$ obtained based on the images of the seismically active area (1) 128 days and (2) 48 days before the earthquake and (3) 73 days after the earthquake, as well as based on the image (D) of the aseismic area. Differences between the densities of strokes in the (E) seismically active and (F) aseismic areas.

the aseismic test site are insignificant and the features typical of earthquakes are unidentifiable. The use of the other spectral channels for the both sets of images has yielded similar results. 

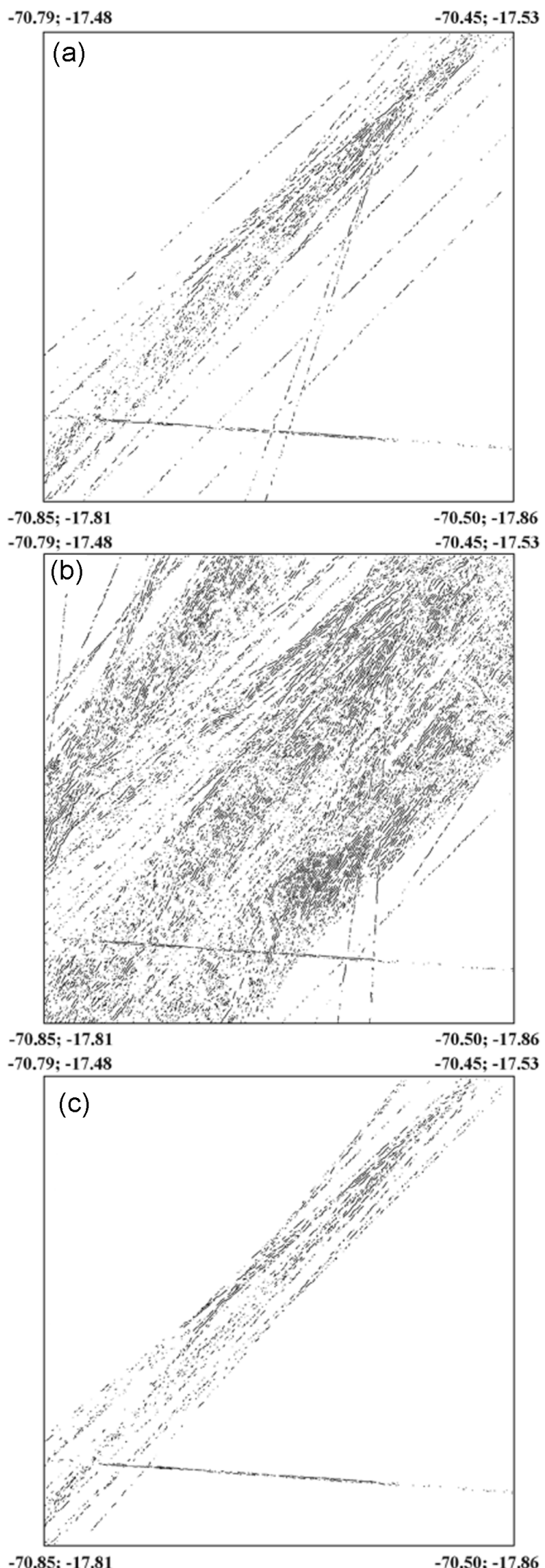

Figure 11. Lineaments obtained from the images of the seismically active area (a) 128 days and (b) 48 days before the earthquake as well as (c) 73 days after the earthquake. Threshold 120.
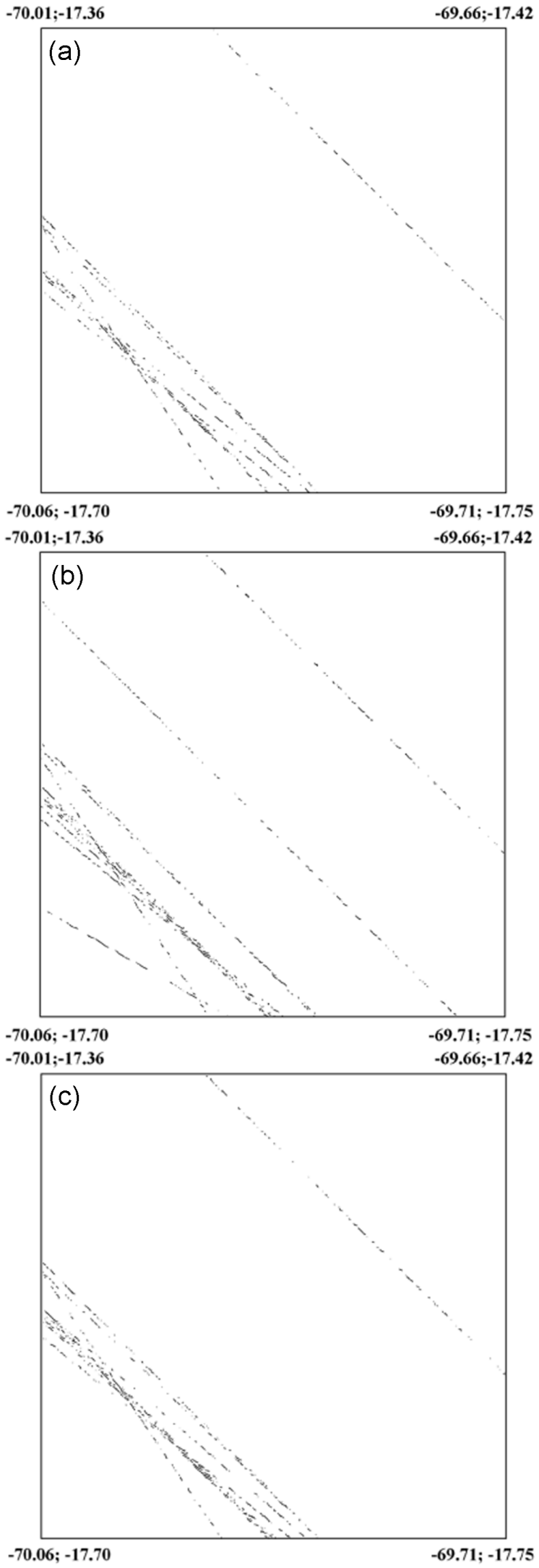

Figure 12. The same as in Figure 11 for the aseismic area. 


\section{Application of the Automated Lineament Analysis to Prediction of Slope Processes and Tracing of Groundwater Flow Paths}

The automated lineament analysis allows locating sites of colluvium and sliding. The former are characterized by the increased total density of strokes per all trend azimuths, which is related with the higher rock fracturing responsible for colluviums. The latter feature higher density of strokes along the certain trend azimuths.

An illustration of the aforesaid may be the data of the automated lineament analysis performed for extensive sliding processes in the Mzymta river basin in the Krasnaya Polyana area (Figure 13a). The analysis used aerophotos at a scale of $1: 30,000,1: 1000$ and $1: 5500$, LANDSAT images obtained using scanner Enhanced Thematic Mapper Plus (ETM+), providing recording in 6 channels with a resolution of $30 \mathrm{~m} /$ pixel, in one infrared channel with a resolution of $60 \mathrm{~m} /$ pixel and the concurrent panchromatic photography at a resolution of $15 \mathrm{~m} /$ pixel and a swath width of $170 \mathrm{~m}$ per each channel, QuickBird image with a high resolution of $1 \mathrm{~m} /$ pixel, as well as surface contour and geological maps.

The major extent of the Mzymta river valley (from Krasnaya Polyana to the Estosadok settlement) is oriented across the morphostructures of the Caucasus. Above the Estosadok settlement, the valley of the Mzymta river abruptly turns southeastward in conformity with the general strike of the Caucasus morphostructures while the tributaries of the river become transversal to these morphostructures Figure 13 ). The elongation lines resultant from the analysis of the digital relief model (DRM) conform with the strike of the morphostructures, whereas the elongation lines obtained from satellite images fit with the Mzymta river valley zones of faulting and jointing oriented across the discussed morphostructures. This inconsistency between the elongation lines is quite understandable for DRM shows the morphostructural (relief) lineaments and the images present the landscape lineaments which are related both with the relief lineaments and with the fractures and fault zones unpronounced in the relief but traceable from a set of the landscape signs.

Examination of densities of strokes of different trend azimuths after the lineament analysis of the synthesized satellite image (Figure 13p) and DRM yields that there is generally no correlation between the anomalous densities of strokes and landslide areas. This correlation is only observed in case of the anomalous density of strokes with the trend azimuths at 45 and $135^{\circ}$ (Figure 13, and Figure 13d).

The first trend azimuth at $45^{\circ}$ is crosswise relative to the tributaries of the Mzymta river, the second trend azimuth at $135^{\circ}$ crosses the valley of the Mzymta river. This means that the key factor for the development of landsliding process is not the overall fracturing of rock mass but the increased density of faults and fractures transversal to the river valleys, which are traced as strokes in the automated lineament analysis of satellite images.

This regularity is understandable as the cross faulting and fracturing zones are the flow paths of interstitial water from fractures and veins toward the outlets in the river valleys.
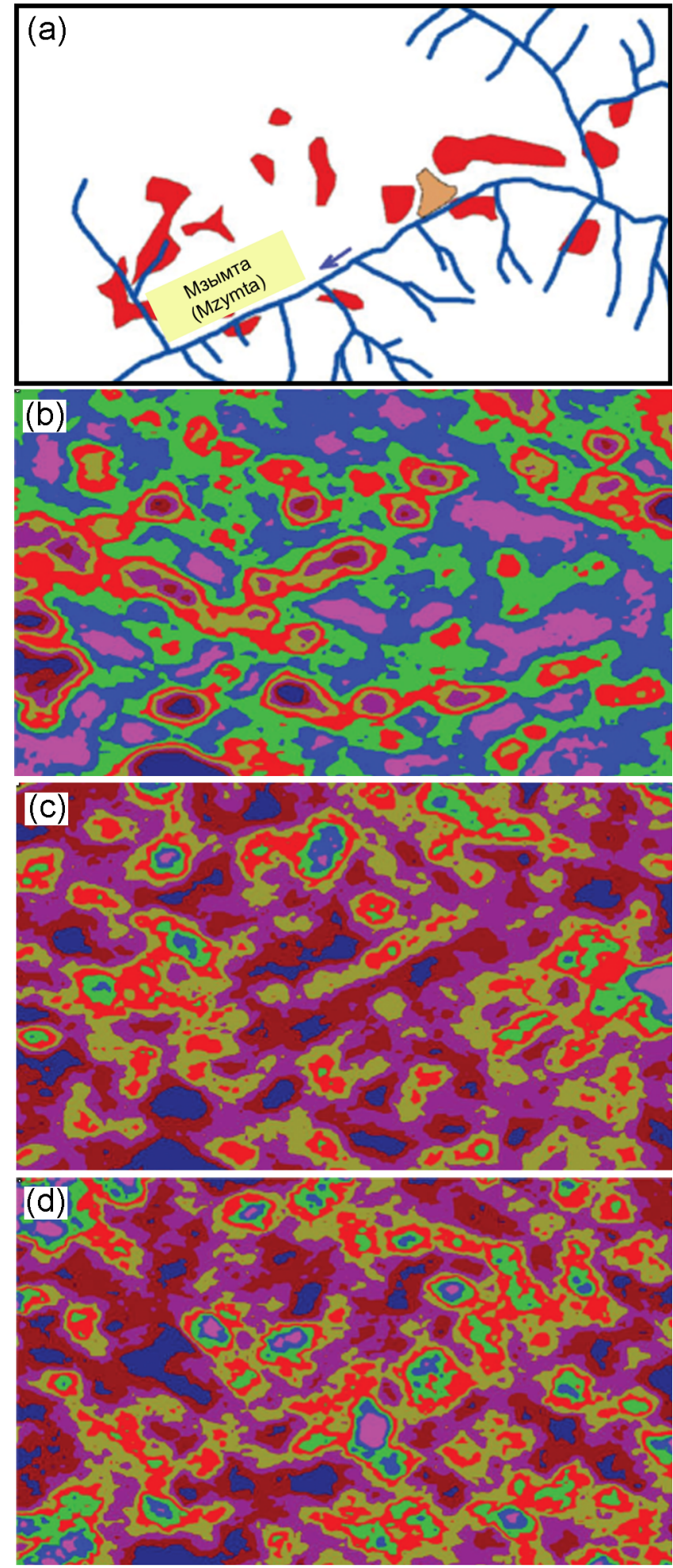

Figure 13. Resultant data of the lineament analysis.

Groundwater wets slopes, which results in their downward displacement (landsliding).

Extensive landsliding in the region of Krasnaya Polyana is conditioned by its geology represented by jointed terri- 
gene (mostly clayey and fine-detrital rocks) and terrigenecarbonate rocks that are readily wettable and slide down the slopes. In case there is no wetting, colluviums rather than landsliding develops.

The revealed correlation enabled predicting new landslide areas on the left bank of the Mzymta river, between the mouths of the Rzhanka and Pelukh rivers, in the basin of the Gelion rivers 1, 2 and 3, near the system of ski-jumps, as well as in some areas on the right bank of the Mzymta river, where an increase in the density of strokes across the valleys of the Mzymta river and its tributaries is observed. The prediction was proved during the field surveys in JulyAugust 2014 [Zverev and Zverev, 2015].

Finally, the presented procedure of the automated lineament analysis allows detection of lineaments of different hierarchical levels at a high statistical significance. The result is the improved objectiveness and completeness of identification of geodynamic and geoecological features in the areas under analysis, connected with the rock mass jointing and induced hydrodynamic processes and slope events. The procedure enables efficient estimation of jointing over vast areas, tracing of pathways of groundwater and detection of most favorable sites for landsliding and other slope processes using satellite images having mean and high resolution.

\section{References}

Bondur, V. G., A. T. Zverev (2005), A method of earthquake forecast based on the lineament analysis of satellite images, Doklady Earth Sciences, 402, No. 4, 561-567.
Kats, Yu. G., A. I. Poletaev (1986),

Basic Lineament Tectonics, Nedra, Moscow. (in Russian)

Malinnikov, V. A., D. V. Uchaev, Dm. V. Uchaev, S. Kh. Fam (2011), Algorithms and programs for the lineament analysis of digital images of the earth surface, Izv. Vuzov. Geodez. Aerofotos., No. 1, 67-73.

Nechaev, Yu. V. (2010), Lineaments and Tectonic Fracturing: Remote Survey of Inner Structure of the Lithosphere, IFZ RAN, Moscow. (in Russian)

Politaev, A. I. (2001), Lineament method, Ekolog. Vestnik, No. 3, $12-28$

Savinykh, V. P., et al. (2012), Automated technique for decoding and analysis of linear and ring structures in satellite images, Izv. Vuzov. Geodez. Aerofotos., No. 6, 53-65.

Zlatopolsky, A. A. (2008), Method to measure orientation characteristics of the remote sensing data (LESSA technology), Current Issues of the Remote Earth Sensing, Issue 5, Volume 1 p. 102-112, Azbuka, Moscow. (in Russian)

Zverev, A. V., A. T. Zverev (2015), Application of automated lineament analysis of satellite images in prospecting oil and gas, prediction of earthquakes and slope processes and in tracing of flow paths of groundwater, Izv. Vyzov, Geolog. Razvedk., No. $6, \quad 14-20$.

O. N. Malinnikova and V. N. Zakharov, Institute of Integrated Mineral Development - IPKON RAS, 4 Kryukovsky tupik, 111020 Moscow, Russia. (vnzakharov@gmail.com)

V. A. Malinnikov, A. T. Zverev, and A. V. Zverev, Moscow State University of Geodesy and Cartography, 4 Gorokhovsky pereulok, 105064 Moscow, Russia. (malinnikov@mail.ru) 